\title{
Diversity and Biogeography of Sooty Blotch and Flyspeck Fungi on Apple in the Eastern and Midwestern United States
}

\author{
María M. Díaz Arias, Jean C. Batzer, Thomas C. Harrington, Amy Wang Wong, Steven C. Bost, \\ Daniel R. Cooley, Michael A. Ellis, John R. Hartman, David A. Rosenberger, George W. Sundin, \\ Turner B. Sutton, James W. Travis, Michael J. Wheeler, Keith S. Yoder, and Mark L. Gleason
}

First, second, third, and fifteenth authors: Department of Plant Pathology, Iowa State University, Ames; fourth author: Facultad de Ciencias Agroalimentarias, Universidad de Costa Rica, San José, Costa Rica; fifth author: University of Tennessee, Soil, Plant and Pest Center, Nashville; sixth author: Department of Plant, Soil and Insect Science, University of Massachusetts, Amherst; seventh author: Department of Plant Pathology, The Ohio State University, Ohio Agricultural Research and Development Center, Wooster; eighth author: Plant Pathology Department, University of Kentucky, Lexington; ninth author: Hudson Valley Laboratory, Cornell University, Highland, NY; tenth author: Department of Plant Pathology, Michigan State University, East Lansing; eleventh author: Department of Plant Pathology, North Carolina State University, Raleigh; twelfth author: Penn State University Fruit Research and Extension Center, Biglerville, PA; thirteenth author: University of Georgia Cooperative Extension, Ellijay; and fourteenth author: Virginia Tech University Agricultural Research and Extension Center, Winchester.

Accepted for publication 17 December 2009.

\begin{abstract}
Díaz Arias, M. M., Batzer, J. C., Harrington, T. C., Wong, A. W., Bost, S. C., Cooley, D. R., Ellis, M. A., Hartman, J. R., Rosenberger, D. A., Sundin, G. W., Sutton, T. B., Travis, J. W., Wheeler, M. J., Yoder, K. S., and Gleason, M. L. 2010. Diversity and biogeography of sooty blotch and flyspeck fungi on apple in the eastern and midwestern United States. Phytopathology 100:345-355.

Sooty blotch and flyspeck (SBFS) fungi on apple fruit were sampled from nine orchards in four midwestern U.S. states during 2000 and 30 orchards in 10 eastern U.S. states during 2005 in order to estimate taxonomic diversity and discern patterns of geographic distribution. Forty apple fruit per orchard were arbitrarily sampled and colonies of each mycelial phenotype were counted on each apple. Representative colonies were isolated, cultures were purified, and DNA was extracted. For representative isolates, the internal transcribed spacer (ITS) and large subunit (LSU) regions of ribosomal DNA were amplified and sequenced. In total, 60 SBFS putative species were identified based on ITS sequences and morphological characteristics; 30 of these were discovered in the 2005

matched to the original isolates on the basis of mycelial type and ITS sequence. Parsimony analysis for LSU sequences from both surveys revealed that 58 putative SBFS species were members of the Dothideomycetes, 52 were members of the Capnodiales, and 36 were members of the Mycosphaerellaceae. The number of SBFS species per orchard varied from 2 to 15. Number of SBFS species and values of the Margalef and Shannon indexes were significantly $(P<0.05)$ lower in 21 orchards that had received conventional fungicide sprays during the fruit maturation period than in 14 unsprayed orchards. Several SBFS species, including Schizothyrium pomi, Peltaster fructicola, and Pseudocercosporella sp. RH1, were nearly ubiquitous, whereas other species, such as Stomiopeltis sp. RS5.2, Phialophora sessilis, and Geastrumia polystigmatis, were found only within restricted geographic regions. The results document that the SBFS complex is far more taxonomically diverse than previously recognized and provide strong evidence that SBFS species differ in geographic distribution. To achieve more efficient management of SBFS, it may be necessary to understand the environmental biology of key SBFS species in each geographic region.
\end{abstract} survey. Modified Koch's postulates were fulfilled for all 60 species in an Iowa orchard; colonies resulting from inoculation of apple fruit were
Additional keywords: polymerase chain reaction.
Sooty blotch and flyspeck (SBFS) is a disease caused by a complex of saprophytic fungi that colonize the epicuticular wax layer of apple (Malus $\times$ domestica Borkh.) and several other fruit crops in humid production regions worldwide $(5,15,46,48)$. In the eastern half of the continental United States, SBFS is a major problem for commercial apple growers because the dark blemishes of SBFS colonies result in downgrading fruit from fresh-market to processing use, with economic losses as high as $90 \%(9,31$, 38,46).

To suppress SBFS and fruit rots, most apple growers in this region apply fungicide sprays every 1 to 2 weeks from 7 to 10 days after petal fall until shortly before harvest. This strategy entails as many as 10 sprays per season and is costly, time consuming, and potentially hazardous to both environmental quality and human health $(7,8)$. Warning systems for SBFS $(7,18)$ have

Corresponding author: M. L. Gleason; E-mail address: mgleason@ iastate.edu

doi:10.1094/PHYTO-100-4-0345

(C) 2010 The American Phytopathological Society potential to reduce fungicide use substantially but their performance has been erratic $(1,11)$, possibly because of insufficient knowledge of the identity and environmental biology of SBFS fungi.

Identification based solely on morphological criteria is impracticable because few SBFS species sporulate readily $(5,12,20$, 26,36). The disease was initially attributed to a single fungus, Dothidea pomigena; later, however, sooty blotch (the term denoting colonies that produce dark mycelial mats on the apple cuticle) and flyspeck (groupings of black dots lacking a visible mycelial matrix) were determined to have distinct causal agents, Gloeodes pomigena and Schizothyrium pomi, respectively $(2,9$, 44). In the 1990s, Sutton and co-workers presented morphological evidence that at least three species caused sooty blotch in North Carolina: Peltaster fructicola, Leptodontidium elatius, and Geastrumia polystigmatis $(23,25,26,38,46)$.

Molecular tools are useful for studying the phylogenetic relationships of filamentous fungi and relating them to host specificity, geographical distribution, and phenotype $(14,17,28,29)$. The internal transcribed spacer region (ITS) of the ribosomal DNA (rDNA) is often used to delineate putative species in combi- 
nation with morphology, whereas the large subunit (LSU) of rDNA is used to place taxa at the family and ordinal level $(3,5$, $13,32,40,43,45)$. By combining morphological description with parsimony analysis of rDNA, Batzer et al. (5) determined that SBFS colonies sampled from nine orchards in four midwestern U.S. states were caused by at least 30 putative species of fungi in 11 anamorph genera. Several of the newly discovered SBFS species differed significantly from others in phenology (34) and sensitivity to widely used fungicides (41). These findings suggested that identifying SBFS species accurately could lead to more effective disease management.

The first indication that assemblages of SBFS fungi differed among geographic regions emerged from a survey of mycelial types in North Carolina apple orchards (38). In a survey of apple fruit from 10 midwestern and eastern U.S. states in 1992 and 9 states in 1993, Johnson et al. (26) documented that Geastrumia polystigmatis occurred in Michigan and New York and that $L$. elatius occurred in New York and Illinois as well as in North Carolina. However, many of the SBFS isolates in these surveys could not be identified solely on the basis of morphological evidence. Based on these pioneering studies, we hypothesized that broader surveys utilizing both morphological and genetic evidence would reveal previously undiscovered SBFS species and regional differences in SBFS species assemblages. Therefore, the objectives of the present study were to (i) characterize diversity and taxonomic relationships of the SBFS fungal complex in the eastern and midwestern United States and (ii) discern biogeographic patterns of species distribution. A portion of the data was published previously (5).

\section{MATERIALS AND METHODS}

Sampling sites. Within 2 weeks before harvest during September to October, apple fruit exhibiting SBFS signs were arbitrarily sampled from 9 sites in four midwestern U.S. states (Iowa, Wisconsin, Missouri, and Illinois) in 2000 (5) and 30 sites in 10 states in the eastern U.S. (Michigan, Ohio, New York, Massachusetts, Pennsylvania, Virginia, North Carolina, Georgia, Tennessee, and Kentucky) in 2005 (Fig. 1). Sites included managed and abandoned commercial orchards as well as home orchards. Forty apple fruit were arbitrarily sampled from $\leq 40$ trees per orchard. The most commonly sampled cultivar was Golden Delicious (Table 1). Apple fruit were transported to Iowa State University (ISU) in padded cardboard boxes.

Colony characterization. At ISU, apple fruit were inspected under a dissecting microscope. On each apple, the number of SBFS colonies of each of the following mycelial types was counted: flyspeck, discrete speck, ramose, ridged honeycomb, punctate, fuliginous, and compact speck (5). Additional characteristics, such as morphology of colony margins and size, shape, and density of sclerotium-like bodies, were also noted. In all, 5 to 15 representative colonies of each mycelial type were selected and labeled from a subsample of 10 to 15 apple fruit from each orchard, for a total of $\approx 500$ and 2,000 colonies in 2000 and 2005, respectively. To minimize contamination of cultures by multiple species, colonies selected for isolation did not visibly overlap with other SBFS colonies on the apple surface. Isolation, purification, and long-term storage of 399 and 1,461 fungal strains from the 2000 and 2005 surveys, respectively, were performed as described by Batzer et al. (5) and Díaz Arias (10). Segments of apple peel containing remnants of the colonies that had been sampled for isolation were preserved by excising the peel and pressing it between paper towels until dry; dried peels were stored at room temperature in multiwell tissue culture plates (Costar; Corning Inc., Corning, NY). The SBFS colony on each peel was digitally photographed under a dissecting microscope.

Putative species designation. Putative species were delineated using ITS sequences and morphological characteristics on apple

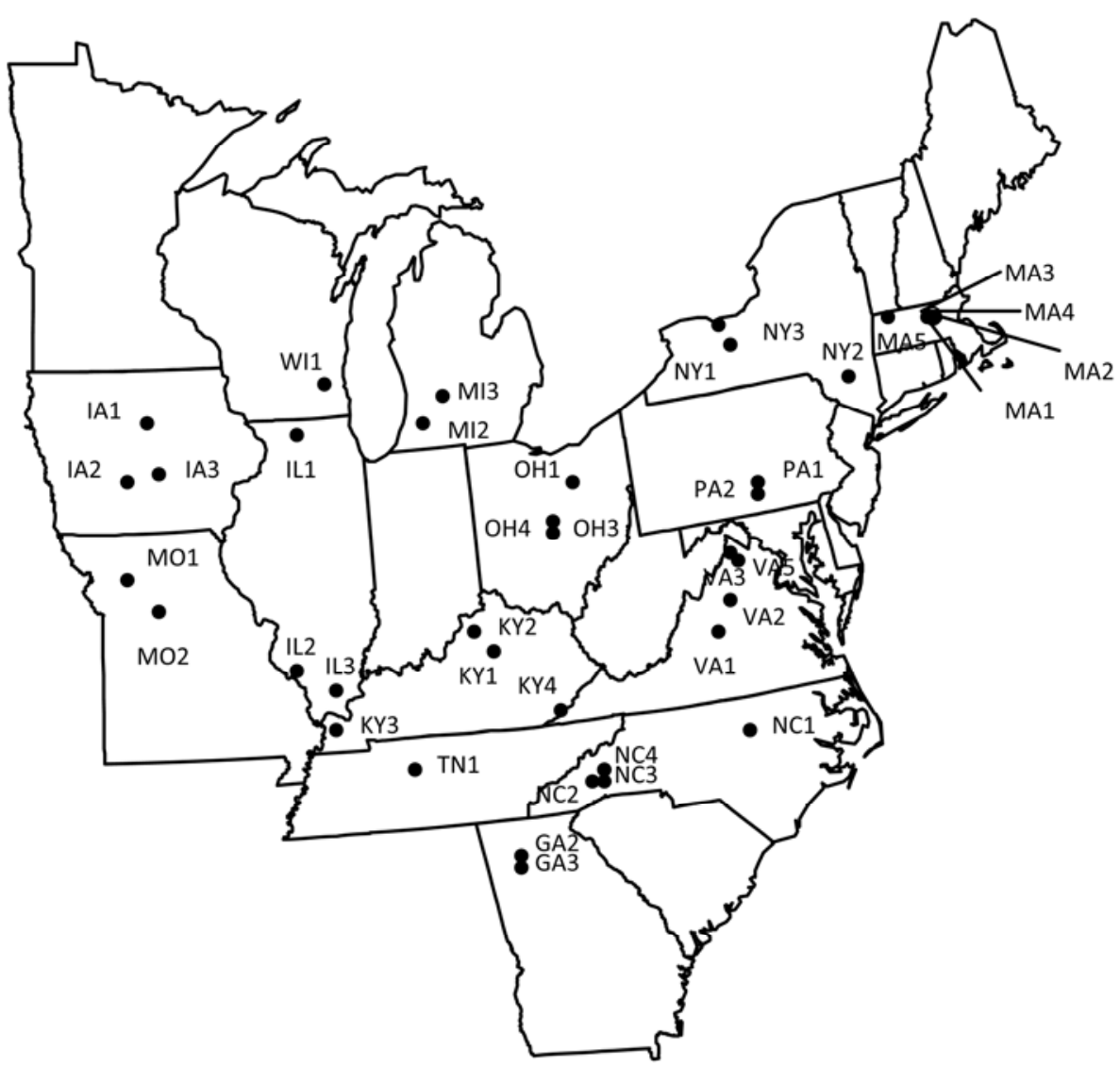

Fig. 1. Location of the 39 orchards from which apple fruit infested with signs of sooty blotch and flyspeck were sampled in 2000 and 2005 . 
and in culture $(5,10)$. One to four representative isolates of each mycelial type on apple from each sampled orchard were sequenced, for a total of 1,069 sequences (358 and 711 for the 2000 and 2005 surveys, respectively). Length of ITS sequences was 458 to 534 bp $(5,10)$. Subsets of taxa with similar sequences were analyzed separately to prevent ambiguous alignments due to large insertions or deletions in the ITS data set. Sixteen alignments of ITS sequences were used to delineate putative species (10). Maximum parsimony analyses were performed for each alignment using PAUP* version $4.0 \mathrm{~b} 10$ for 32-bit Microsoft Windows $(5,10,40)$.

Morphology of isolates grouped into putative species based on ITS parsimony analysis was characterized on apple fruit and on artificial media. Genus designations were determined by anamorph morphology $(5,10)$.

For each putative species, a modified Koch's postulates procedure was performed during four growing seasons in an orchard at the ISU Horticulture Research Farm near Gilbert, IA $(5,10)$. Briefly, after immature apple fruit were surface sterilized with ethanol, a suspension of mycelial fragments and conidia of representative isolates was swabbed onto the fruit, and the fruit were immediately enclosed in Fuji bags (Kobayshi Bag Manufacturing Co. Ltd., Iasa, Nagano, Japan). At harvest, bags were removed, mycelial type of fungal colonies was compared with that of the inoculated isolate, and identity of the reisolated fungus was confirmed by comparing the ITS sequence with that of the original isolate.

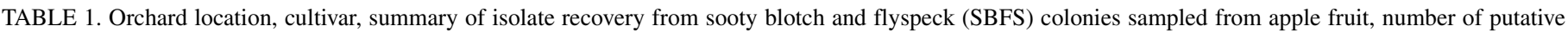
species identified, and species diversity in 39 orchards in the eastern and midwestern United States

\begin{tabular}{|c|c|c|c|c|c|c|c|c|c|c|c|c|}
\hline \multicolumn{5}{|c|}{ Orchard $^{\mathrm{r}}$} & \multirow[b]{2}{*}{ Colonies $^{\mathrm{u}}$} & \multirow[b]{2}{*}{ Types $^{v}$} & \multirow[b]{2}{*}{ Attempted $^{\mathrm{w}}$} & \multirow[b]{2}{*}{ Successful ${ }^{\mathrm{x}}$} & \multirow[b]{2}{*}{ Cultures $^{\mathrm{y}}$} & \multirow[b]{2}{*}{ SBFS $^{z}$} & \multicolumn{2}{|c|}{ Species diversity } \\
\hline Code & Long. & Lat. & Cultivar & Spray ${ }^{\mathrm{t}}$ & & & & & & & MI & SI \\
\hline GA2 & -84.50925 & 34.71445 & Golden Delicious & 1 & 51 & 6 & 72 & 17 & 17 & 5 & 0.53 & 1.95 \\
\hline GA3 & -84.41414 & 34.64939 & Golden Delicious & 1 & 30 & 7 & 90 & 25 & 24 & 11 & 1.41 & 2.56 \\
\hline IA1 & -93.31043 & 42.51855 & Golden Delicious & 1 & 27 & 6 & 72 & 20 & 15 & 7 & 0.94 & 2.67 \\
\hline IA2 & -93.48052 & 41.34888 & Golden Delicious & 2 & 91 & 7 & 90 & 26 & 25 & 13 & 1.43 & 3.19 \\
\hline IA3 & -92.87919 & 41.39307 & Golden Delicious & 1 & 95 & 7 & 90 & 15 & 7 & 6 & 0.60 & 2.27 \\
\hline IL1 & -89.15663 & 42.32575 & Golden Delicious & 1 & 48 & 5 & 61 & 12 & 9 & 5 & 0.55 & 1.11 \\
\hline IL2 & -89.87836 & 37.95379 & Golden Delicious & 2 & 33 & 7 & 90 & 30 & 20 & 10 & 1.21 & 2.68 \\
\hline IL3 & -88.65504 & 37.45984 & Golden Delicious & 2 & 28 & 6 & 72 & 21 & 19 & 12 & 1.52 & 2.77 \\
\hline KY1 & -84.69616 & 37.99534 & Golden Delicious & 2 & Tmtc & 5 & 65 & 62 & 52 & 15 & 1.79 & 2.89 \\
\hline KY2 & -85.05524 & 38.45239 & Golden Delicious & 1 & 30 & 4 & 50 & 9 & 6 & 6 & 0.71 & 1.43 \\
\hline KY3 & -88.69779 & 37.08633 & Golden Delicious & 2 & 147 & 5 & 60 & 45 & 41 & 11 & 1.11 & 2.11 \\
\hline KY4 & -83.27374 & 36.78287 & Golden Delicious & 1 & $*$ & 7 & 108 & 58 & 34 & 10 & 1.27 & 2.70 \\
\hline MA1 & -71.51437 & 42.41031 & Grimes Golden & 1 & 11 & 6 & 72 & 26 & 22 & 7 & 1.00 & 1.88 \\
\hline MA2 & -71.61803 & 42.38998 & McIntosh & 1 & 7 & 6 & 72 & 37 & 24 & 8 & 1.25 & 1.38 \\
\hline MA3 & -71.56911 & 42.50095 & McIntosh & 1 & 6 & 3 & 45 & 22 & 6 & 3 & 0.37 & 1.37 \\
\hline MA4 & -71.61056 & 42.44418 & McIntosh & 1 & 7 & 2 & 24 & 12 & 3 & 2 & 0.18 & 0.12 \\
\hline MA5 & -72.62319 & 42.56459 & Golden Delicious & 1 & 115 & 4 & 60 & 58 & 21 & 4 & 0.49 & 1.67 \\
\hline MI2 & -86.10859 & 42.24392 & Golden Delicious & 2 & Tmtc & 6 & 80 & 37 & 29 & 8 & 0.85 & 2.66 \\
\hline MI3 & -86.19000 & 42.55214 & Golden Delicious & 2 & 4 & 5 & 60 & 20 & 20 & 8 & 1.57 & 2.39 \\
\hline MO1 & -93.65358 & 39.74801 & Golden Delicious & $\mathrm{Nd}$ & Tmtc & 5 & 60 & 19 & 16 & 7 & 0.78 & 2.66 \\
\hline $\mathrm{MO} 2$ & -92.76435 & 39.02161 & Golden Delicious & & 38 & 6 & 72 & 58 & 28 & 10 & 1.19 & 2.93 \\
\hline $\mathrm{NC} 1$ & -78.49260 & 35.66980 & Golden Delicious & 2 & 114 & 7 & 90 & 58 & 46 & 13 & 1.43 & 2.90 \\
\hline $\mathrm{NC} 2$ & -82.39420 & 35.29890 & Golden Delicious & 1 & Tmtc & 4 & 60 & 27 & 14 & 4 & 0.40 & 0.54 \\
\hline $\mathrm{NC} 3$ & -82.39660 & 35.31320 & Golden Delicious & 1 & 12 & 3 & 45 & 22 & 13 & 3 & 0.35 & 0.82 \\
\hline $\mathrm{NC} 4$ & -82.55888 & 35.42721 & Golden Delicious & 1 & 17 & 2 & 20 & 14 & 6 & 2 & 0.16 & 0.73 \\
\hline NY1 & -77.02251 & 42.87385 & Jonagold & 2 & 70 & 6 & 72 & 53 & 34 & 10 & 1.13 & 2.60 \\
\hline NY2 & -74.09064 & 41.67057 & GoldRush & 3 & 24 & 7 & 84 & 56 & 27 & 8 & 1.02 & 1.62 \\
\hline NY3 & -77.06855 & 43.25849 & Greening & 1 & 16 & 7 & 90 & 33 & 29 & 9 & 1.22 & 1.25 \\
\hline $\mathrm{OH} 1$ & -81.91842 & 40.77872 & Golden Delicious & 2 & 87 & 6 & 72 & 32 & 27 & 8 & 0.87 & 2.01 \\
\hline $\mathrm{OH} 3$ & -82.53267 & 40.15306 & GoldRush & 2 & 88 & 6 & 72 & 30 & 16 & 8 & 0.86 & 1.97 \\
\hline $\mathrm{OH} 4$ & -82.66374 & 40.05870 & Prime Gold & 1 & 57 & 4 & 60 & 27 & 23 & 6 & 0.65 & 1.64 \\
\hline PA1 & -77.23092 & 39.97889 & Ginger Gold & 1 & 12 & 6 & 75 & 55 & 23 & 9 & 1.29 & 1.07 \\
\hline PA2 & -77.24760 & 39.98757 & NW Greening & 3 & 38 & 4 & 50 & 23 & 22 & 7 & 0.85 & 1.56 \\
\hline TN1 & -86.74932 & 36.06322 & Golden Delicious & 2 & 530 & 7 & 90 & 41 & 33 & 12 & 1.13 & 2.25 \\
\hline VA1 & -78.89500 & 37.73052 & Golden Delicious & 1 & 47 & 5 & 60 & 32 & 27 & 5 & 0.53 & 0.15 \\
\hline VA2 & -78.32941 & 38.49756 & Golden Delicious & 1 & 13 & 5 & 60 & 26 & 18 & 10 & 1.68 & 2.79 \\
\hline VA3 & -78.15307 & 39.18531 & Golden Delicious & 1 & 37 & 4 & 50 & 36 & 14 & 4 & 0.47 & 0.58 \\
\hline VA5 & -78.28537 & 39.11640 & Granny Smith & 2 & 76 & 5 & 60 & 48 & 21 & 6 & 0.62 & 2.06 \\
\hline WI1 & -88.25142 & 42.57697 & Golden Delicious & $\mathrm{Nd}$ & 34 & 4 & 50 & 28 & 20 & 8 & 0.94 & 2.06 \\
\hline
\end{tabular}

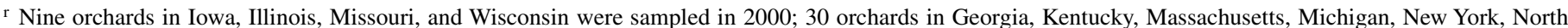
Carolina, Ohio, Pennsylvania, Tennessee, and Virginia were sampled in 2005. Codes: states abbreviated as follows: Georgia = GA; Iowa = IA; Illinois = IL; Kentucky = KY; Massachusetts = MA; Michigan = MI; Missouri = MO; North Carolina = NC; New York = NY; Ohio = OH; Pennsylvania = PA; Tennessee = TN; Wisconsin = WI. Long. = longitude and Lat. = latitude (degrees).

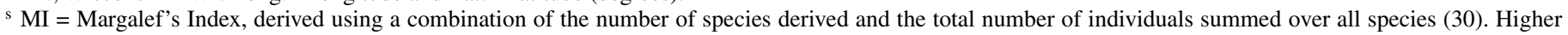
numbers indicate greater diversity. SI = Shannon Index, which incorporates species richness with the estimated proportion of individuals of a given species to the total number of individuals in the orchard (relative abundance) (33). Higher numbers indicate greater diversity.

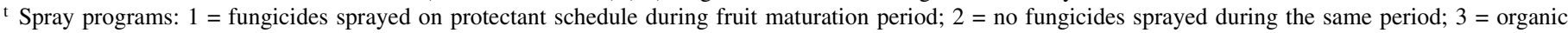
orchard; $\mathrm{Nd}=$ information not determined.

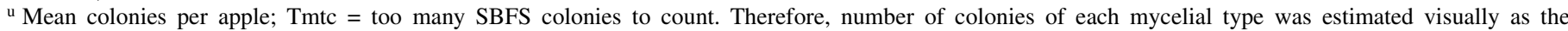
percentage of fruit area covered by that mycelial type.

$\checkmark$ Total number of SBFS mycelial types noted on 40 apple fruit per orchard.

${ }^{w}$ Number of attempted isolations.

${ }^{x}$ Number of successful isolations.

${ }^{y}$ Cultures sequenced: internal transcribed spacer (ITS) region of ribosomal DNA.

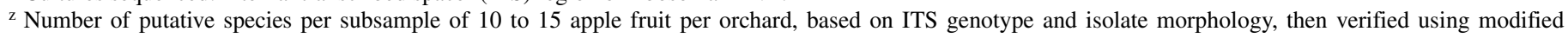
Koch's postulates. 
Analysis of LSU region. Putative species were taxonomically characterized by analyzing a portion of the LSU $28 \mathrm{~S}$ region of rDNA. DNA was extracted from representative isolates of each putative species within each orchard $(5,10)$. The primer pair used for amplification and sequencing was LROR/LR5 (43). Procedures described by Batzer et al. (5) were employed to amplify, purify, and quantify 518 polymerase chain reaction products (177 from the 2000 survey and 341 from the 2005 survey). Automated sequencing was performed at the ISU DNA Sequencing and Synthesis Facility. The length of partial LSU sequences was $\approx 850 \mathrm{bp}$, including gaps. Preliminary alignments were generated using CLUSTAL-X (42) with gap opening and gap extension parameters of $50: 5$, and these alignments were manually optimized using Bioedit (16). Taxa with identical LSU sequences were eliminated from the data block, reducing the number of SBFS taxa in the analysis to 60 sequences. Sequences of isolates from previously identified SBFS species (26) were included in the alignment.

Preliminary trees were generated that included all 60 SBFS taxa recovered from our surveys. To enhance readability of trees, the taxa were divided into two data sets of 24 and 36 putative species, respectively, and sequences from GenBank of related taxa were added to generate two trees. For the first data set, Agaricus bisporus (DQ071710) (a Basidiomycete) was chosen to be the outgroup, because preliminary analysis placed the SBFS taxa in two classes of Ascomycota (Sordariomycetes and Dothideomycetes). This alignment also contained Capnodium coffea (DQ247800) and several sequences of Mycosphaerella spp. that served to place the 36 putative SBFS species used in the second alignment to family, order, and subclass. The outgroup for the second data set was Capnodium coffea; this matrix contained the putative species that grouped with Mycosphaerella spp. in preliminary trees. For both trees, maximum parsimony analysis was performed using PAUP (40). Heuristic searches were conducted with random sequence addition and tree bisection-reconnection branch swapping algorithms, collapsing zero-length branches, and saving all minimal length trees. Maxtrees was set at 10,000. Alignable gaps were treated as a fifth base. All characters were given equal weight. To assess the robustness of clades and internal branches for data sets, a strict consensus of the most parsimonious trees was generated and a bootstrap analysis of 1,000 replications was performed.

Species diversity. After putative species were delineated based on ITS genotype and culture morphology, the number of species found at each of the 39 sites was determined. Two additional diversity indexes were calculated for each site: the Shannon index (33), a measure of proportional species abundance (30); and Margalef's richness index, which accounts for situations in which one or a few species are dominant and the rest are rare (30).

To estimate relative abundance of each putative species in an orchard, the number of colonies identified as belonging to a particular putative species was multiplied by the proportion of colonies of each corresponding mycelial type. For apple fruit that had too many colonies to count individually, the proportion of each mycelial type was estimated visually. A spreadsheet was constructed to determine frequency with which a given mycelial type was associated with more than one putative species in each sampled orchard. Based on mycelial type identification and sequence analysis, $78 \%$ of mycelial types in an orchard were associated with a single putative species. In the $22 \%$ of instances where a mycelial type was associated with $>1$ putative species in a sampled orchard, relative abundance of each species was determined by multiplying the percentage of isolates in the sample with a given mycelial type by the proportion of each putative species exhibiting that mycelial type.

\section{RESULTS}

Isolation and species designation. In total, 60 putative species of the SBFS complex were delineated using ITS sequences and morphological characteristics on apple and in culture $(5,10)$; 30 of these species were found in the 2000 survey and 30 additional species were isolated in the 2005 survey. Previously reported SBFS complex members that were also found included Schizothyrium pomi, Peltaster fructicola, Geastrumia polystigmatis, and Stomiopeltis versicolor $(23,25,26,38,46)$. However, no isolates of L. elatius were recovered in the survey. Furthermore, no isolates resembled the description of Gloeodes pomigena made by Colby in 1920 (9). The survey results and the process for identifying putative species in the SBFS complex for each orchard are summarized in Table 1. The estimated mean number of SBFS colonies per apple was 180 . The number of mycelial types per apple was 2 to 7 . Of 2,516 attempts to isolate pure cultures from signs on apple, $\approx 50 \%$ were successful. Success of isolation was 17 to $96 \%$ per orchard, depending on culturability of individual species and the condition of the fruit when isolations were attempted. Of the 68 genotypes determined from parsimony analysis of the ITS sequences obtained from pure cultures, $88 \%$ (60 putative species) were verified as members of the SBFS complex using the modified Koch's postulates procedures.

Phylogenetic placement of putative species. The first LSU data set contained 51 taxa (including the outgroup taxon A. bisporus) and 824 characters. Of these characters, 286 were parsimony informative, 111 were variable and parsimony uninformative, and 427 were constant. Maximum parsimony analysis of the LSU sequences resulted in 546 equally informative trees, one of which is shown in Figure 2. Parsimony analysis grouped two putative species, Phialophora sessilis and Yeast sp. UI-10, within the Sordariomycetes (29). The remaining 58 taxa were classified as Dothideomycetes (28) (Figs. 2 and 3). Although four putative species, Sterile mycelia sp. FG6, Geastrumia polystigmatis, Ramularia sp. CS2, and Sybren sp. CS1, fell within the Dothideomycetes, they could not be placed to order (Fig. 2). There was strong support ( $82 \%$ bootstrap support) for placing the remaining 55 SBFS taxa in the Dothideomycetidae subclass (Fig. 2). Three isolates of Sterile mycelia sp. UI-6 from Pennsylvania and New York grouped with Myriangium duriaei in the Myrangiales.

Parsimony analysis grouped 53 putative species within the Capnodiales (32) with bootstrap value of $100 \%$ (Figs. 2 and 3). Within the Capnodiales, the five Peltaster spp. formed a strongly supported clade (100\% bootstrap support) but this genus did not group with other taxa at the family level (Fig. 2). The remaining 48 putative species were grouped with $98 \%$ bootstrap support. These taxa segregated into three distinct clades: Teratosphaeriaceae, Schizothyriaceae, and Mycosphaerellaceae (Figs. 2 and 3). Five putative species, including Sterile mycelia sp. MB1 and Pseudocercospora spp. FS4, FG1.1, FG1.9, and FG1.2, resided in the Teratosphaeriaceae with $89 \%$ bootstrap support. Parsimony analysis also grouped two sister clades ( $76 \%$ bootstrap support) that included two families, the Schizothyriaceae (96\% bootstrap support) and the Mycosphaerellaceae (54\% bootstrap support) (Fig. 2). Six putative species in the Schizothyriaceae had Zygophiala anamorphs; Pseudocercospora sp. FS5 differed from Zygophiala in conidia morphology but produced the flyspeck mycelial type on apple fruit.

Over half (36 of 60) of the putative species grouped in the Mycosphaerellaceae and were included in the second alignment (Fig. 3). This LSU alignment contained 50 taxa (including the outgroup taxon Capnodium coffea), and 842 characters were used for the analyses. Of these, 149 characters were parsimony informative, 105 characters were variable and parsimony uninformative, and 588 were constant. Maximum parsimony analysis of the LSU sequences resulted in 383 equally parsimonious informative trees, one of which is shown in Figure 3.

Seven putative species formed a strongly supported clade $(98 \%$ bootstrap) with Dissoconium aciculare and D. commune. Four of these putative species produced fuliginous signs on apple and three species produced the discrete speck mycelial type. Fourteen 
putative species from the surveys formed a strongly supported clade $(84 \%)$ with two previously identified species of Stomiopeltis. With the exception of Geastrumia polystigmatis and Sterile mycelia sp. RS6, the Stomiopeltis clade contained all of the ramose mycelial types identified in this survey. Seven putative species in the Stomiopeltis clade produced anamorphs in culture, including Phaeothecoidiella spp. P3 and P4; Houjia spp. FG7.1,
FG7.2, FG7.3; Sporidesmajora FG7.4; and Passalora sp. FG3, and these species exhibited either punctate or fuliginous mycelial types on apple. The remaining 15 putative species were grouped with six Mycosphaerella spp. (59\% bootstrap support) whose LSU sequences were obtained from GenBank. Parsimony analysis grouped Ramularia sp. P5 with M. punctiformis with 94\% bootstrap support. Pseudocercospora spp. LLS1 and LLS2 were

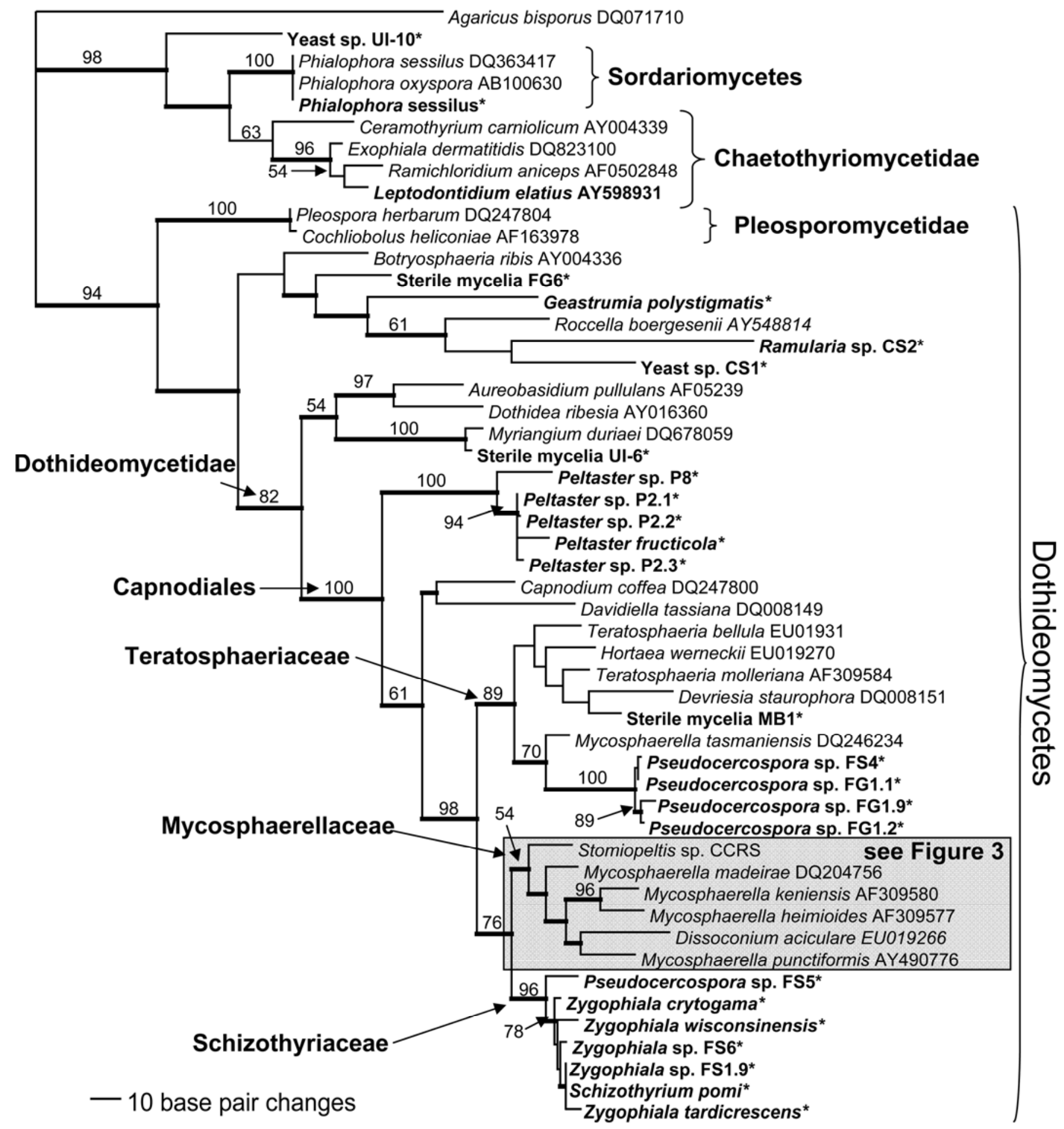

Fig. 2. One of 546 most parsimonious trees determined from partial large subunit sequences ( 874 bp) obtained from sooty blotch and flyspeck (SBFS) isolates on apple from eastern and midwestern U.S. orchards. One isolate for each putative species of SBFS is included, except for some of the SBFS species in Figure 3. Putative species denoted in bold have been documented to cause SBFS on apple; those also denoted with asterisks were isolated during the 2000 and 2005 surveys. Gaps were treated as a fifth base and 47 characters were excluded from the data set. Parsimony informative characters $=273$. Bootstrap values $>50$ derived from 1,000 replications are shown and branches in bold are derived from strict consensus of most parsimonious trees. Tree length $=1,614$; consistency index $(\mathrm{CI})=$ 0.4399 ; homoplasy index $(\mathrm{HI})=0.5601$; retention index $(\mathrm{RI})=0.7135$. The tree is rooted to an Agaricus bisporus sequence (DQ071710) obtained from GenBank. The shaded box denotes the branch that includes most of the SBFS complex groups and is presented in greater detail in Figure 3. 
grouped with a strain of Pseudocercospora isolated from eucalyptus leaves in Thailand (94\% bootstrap support); and Colletogloeum sp. FG2 was grouped with M. marksii (79\% bootstrap support). Three species having Ramichloridium anamorphs formed an unsupported cluster with M. madeirae and Ramichloridium sp. FG9 grouped with Ramichloridium cerophilum with $100 \%$ bootstrap support. Moreover, strict consensus grouped eight putative species in the Pseudocercosporella clade.

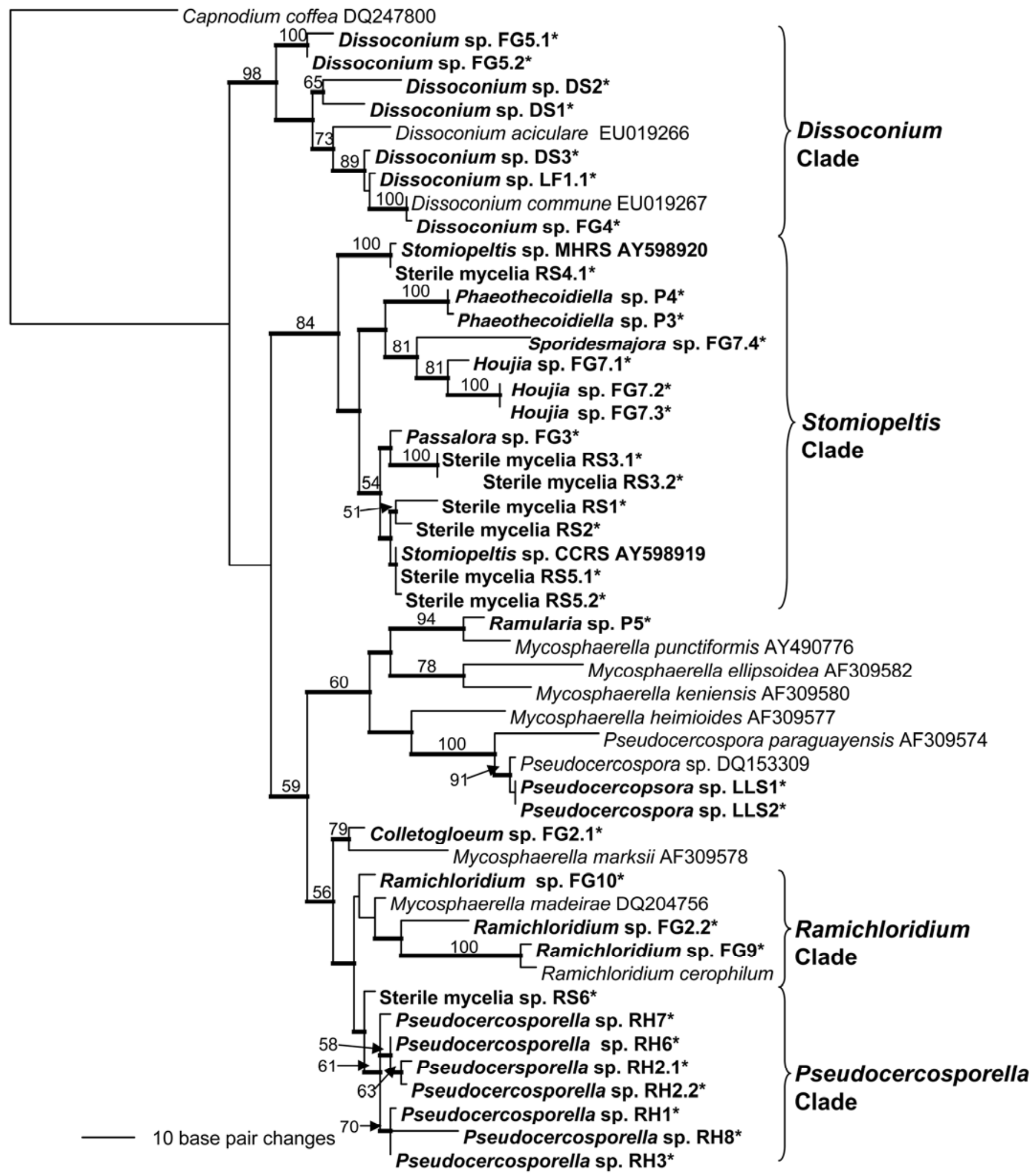

Fig. 3. One of 383 most parsimonious trees determined from partial large subunit sequences ( $842 \mathrm{bp}$ ) obtained from sooty blotch and flyspeck (SBFS) isolates on apple from eastern and midwestern U.S. orchards that formed a well-supported clade in Figure 2. One isolate for each putative species of SBFS that groups with the Mycosphaerellaceae is included. Putative species denoted in bold have been documented to cause SBFS on apple; those also denoted with asterisks were isolated during the 2000 and 2005 surveys. Gaps were treated as a fifth base. Parsimony informative characters $=149$. Bootstrap values $>50$ derived from 1,000 replications are shown and branches in bold are derived from strict consensus of 383 most parsimonious trees. Tree length $=581$; consistency index $(\mathrm{CI})=0.5938$; homoplasy index $(\mathrm{HI})=0.4062$; retention index $(\mathrm{RI})=0.7837$. The tree is rooted to a Capnodium coffea sequence $(\mathrm{DQ} 247800)$. 
Sterilemycelia sp. RS6 was basal to this clade and, in addition to the lack of conidia in culture, produced a ramose mycelial type on apple (Table 2). The remaining seven Pseudocercosporella spp. were grouped with $61 \%$ bootstrap support and exhibited the ridged honeycomb mycelial type on apple (Fig. 3).

Species prevalence and diversity. The most prevalent SBFS species in the 2000 and 2005 surveys were Schizothyrium pomi,

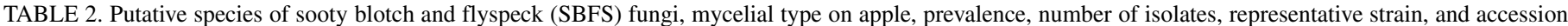
numbers from surveys of 39 apple orchards in the eastern and midwestern United States in 2000 and 2005

\begin{tabular}{|c|c|c|c|c|c|c|c|}
\hline \multirow[b]{2}{*}{ Putative species ${ }^{t}$} & \multirow[b]{2}{*}{ Mycelial type ${ }^{u}$} & \multirow[b]{2}{*}{ Prevalence $^{v}$} & \multirow[b]{2}{*}{ Isolates $^{\mathrm{w}}$} & \multirow[b]{2}{*}{ Representative strain } & \multicolumn{3}{|c|}{ Accession numbers } \\
\hline & & & & & $\operatorname{ITS}^{x}$ & LSU $^{y}$ & $\mathrm{CBS}^{\mathrm{z}}$ \\
\hline Colletogloeum sp. FG2.1 & Fuliginous & 11 & 32 & NY1 3.2F1c & FJ425193 & FJ031986 & CBS 125300 \\
\hline Dissoconium aciculare (DS1) & Discrete speck & 10 & 16 & MSTB4b & AY598874 & AY598912 & CBS 118967 \\
\hline Dissoconium sp. DS2 & Discrete speck & 1 & 2 & MWB6 & na & AY598914 & CBS 118948 \\
\hline Dissoconium sp. DS3 & Discrete speck & 2 & 4 & GA2 38A1a & FJ425203 & FJ147152 & CBS 125301 \\
\hline Dissoconium sp. FG5.1 & Fuliginous & 4 & 7 & UIF3 & AY598877 & AY598916 & CBS 118961 \\
\hline Dissoconium sp. FG5.2 & Fuliginous & 1 & 2 & MI3 34F1a & FJ425205 & FJ147154 & CBS 125648 \\
\hline Dissoconium sp. LF1.1 & Fuliginous & 3 & 5 & OH3 37E1d & FJ425204 & FJ147153 & CBS 125302 \\
\hline Dissoconium commune (FG4) & Fuliginous & 5 & 9 & MSTF2 & AY598876 & AY598915 & CBS 118962 \\
\hline Geastrumia polystigmatis & Ramose & 24 & 131 & NC4 1.8F1a & FJ438389 & FJ147177 & CBS 125303 \\
\hline Houjia pomigena (FG7.1) & Fuliginous & 1 & 1 & $\mathrm{UIF} 2 \mathrm{~b}$ & AY598885 & AY598925 & CBS 125224 \\
\hline Houjia sp. FG7.2 & Fuliginous & 1 & 1 & KY3 13F1d & FJ438377 & FJ147165 & CBS 125228 \\
\hline Houjia yanglingensis (FG7.3) & Fuliginous & 1 & 1 & TN1 2.2F1d & FJ438378 & FJ147166 & CBS 125227 \\
\hline Passalora sp. FG3 & Fuliginous & 2 & 6 & GTF3a & na & AY598926 & CBS 118964 \\
\hline Peltaster sp. P2.1 & Punctate & 3 & 4 & GTE9a & AY598888 & AY598929 & CBS 119464 \\
\hline Peltaster sp. P2.2 & Punctate & 5 & 9 & UIE11b & AY598930 & AY588930 & CBS 118953 \\
\hline Peltaster sp. P2.3 & Punctate & 1 & 1 & KY2 16E1b & FJ438383 & FJ147170 & CBS 125649 \\
\hline Peltaster sp. P8 & Punctate & 2 & 3 & KY3 8E1a & FJ438384 & FJ147171 & CBS 125304 \\
\hline Peltaster fructicola & Punctate & 29 & 121 & KY1 12.2E2b & FJ438382 & AY598928 & CBS 125304 \\
\hline Phaeothecoidiella missouriensis (P3) & Punctate & 1 & 2 & AHE7c & AY598878 & AY598917 & CBS 118959 \\
\hline P. illinoisensis $(\mathrm{P} 4)$ & Punctate & 2 & 3 & UIE3 & AY598879 & AY598918 & CBS 118947 \\
\hline Phialophora sessilis & Punctate & 5 & 6 & NY2 4C1a & FJ438386 & FJ147173 & CBS 125306 \\
\hline Pseudocercospora sp. FG1.1 & Fuliginous & 9 & 25 & MA2 5F1b & FJ438380 & FJ147168 & CBS 125307 \\
\hline Pseudocercospora sp. FG1.2 & Fuliginous & 1 & 1 & MSTF5a & na & AY598899 & CBS 118954 \\
\hline Pseudocercospora sp. FG1.9 & Fuliginous & 2 & 2 & MA2 3.5F1c & FJ438381 & FJ147169 & CBS 125308 \\
\hline Pseudocercospora sp. FS4 & Flyspeck & 1 & 2 & MWA4b & AY598857 & AY598900 & CBS 118945 \\
\hline Pseudocercospora sp. FS5 & Flyspeck & 1 & 3 & MA3 1.3B1a & FJ438371 & FJ355914 & CBS 125309 \\
\hline Pseudocercospora sp. LLS1 & Fuliginous & 2 & 3 & $\mathrm{NC} 122 \mathrm{~F} 2 \mathrm{~d}$ & FJ425192 & FJ025897 & na \\
\hline Pseudocercospora sp. LLS2 & Fuliginous & 1 & 1 & KY3 22D1b & EU605812 & FJ025898 & CBS 125650 \\
\hline Pseudocercosporella sp. RH1 & Ridged honeycomb & 23 & 60 & KY3 20D1a & FJ425195 & FJ031988 & CBS 124417 \\
\hline Pseudocercosporella sp. RH3 & Ridged honeycomb & 12 & 17 & $\mathrm{OH} 134 \mathrm{D} 2 \mathrm{a}$ & FJ425196 & FJ031989 & CBS 125651 \\
\hline Pseudocercosporella sp. RH2.1 & Ridged honeycomb & 4 & 5 & UMD1a & AY598866 & AY598902 & CBS119462 \\
\hline Pseudocercosporella sp. RH2.2 & Ridged honeycomb & 10 & 16 & PA1 31D1a & FJ425197 & FJ031990 & CBS 125652 \\
\hline Pseudocercosporella sp. RH6 & Ridged honeycomb & 1 & 2 & MI3 20F1a & FJ425201 & FJ031994 & CBS 125653 \\
\hline Pseudocercosporella sp. RH7 & Ridged honeycomb & 1 & 1 & GA3 3D1b & FJ425202 & FJ031995 & CBS 125654 \\
\hline Pseudocercosporella sp. RH8 & Ridged honeycomb & 1 & 1 & NY1 3.2D1b & na & FJ147151 & CBS 125655 \\
\hline Ramichloridium sp. FG2.2 & Fuliginous & 2 & 5 & GA3 25G1c & FJ425194 & FJ031987 & CBS 125656 \\
\hline Ramichloridium sp. FG9 & Fuliginous & 4 & 8 & NC1 3F1a & FJ425199 & FJ031992 & na \\
\hline Ramichloridium sp. FG10 & Fuliginous & 3 & 4 & TN1 1.3F1a & FJ425200 & FJ031993 & CBS125310 \\
\hline Ramularia sp. P5 & Punctate & 3 & 3 & UME2 & AY598873 & AY598910 & CBS 119227 \\
\hline Ramularia sp. CS2 & Compact speck & 6 & 11 & $\mathrm{OH} 3$ 9H1c & FJ438390 & FJ147176 & CBS125311 \\
\hline Schizothyrium pomi & Flyspeck & 38 & 108 & VA1 7A1d & FJ425206 & FJ147155 & CBS125312 \\
\hline Sporidesmajora pennsylvaniensis (FG7.4) & Fuliginous & 1 & 1 & PA1 9F1a & FJ438379 & FJ147167 & CBS125229 \\
\hline Sterile mycelia sp. MB1 & Ramose & 2 & 2 & VA1 29D1c & na & FJ355913 & CBS125313 \\
\hline Sterile mycelia sp. RS1 & Ramose & 4 & 4 & PEC6a & AY598882 & AY598921 & CBS118955 \\
\hline Sterile mycelia sp. RS2 & Ramose & 3 & 7 & AHC3a & AY598883 & AY598922 & CBS119228 \\
\hline Sterile mycelia sp. RS3.1 & Ramose & 2 & 2 & MI3 24F1a & FJ438372 & FJ147160 & CBS 125657 \\
\hline Sterile mycelia sp. RS3.2 & Ramose & 1 & 1 & KY4 11.2F2b & FJ438373 & FJ147161 & na \\
\hline Sterile mycelia sp. RS4.1 & Ramose & 4 & 13 & TN1 6.3E2a & FJ438374 & FJ147162 & CBS125314 \\
\hline Sterile mycelia sp. RS6 & Ramose & 3 & 12 & $\mathrm{OH} 16 \mathrm{C} 1 \mathrm{~b}$ & FJ425198 & FJ031991 & CBS125315 \\
\hline Sterile mycelia sp. FG6 & Fuliginous & 1 & 1 & MWF4b & na & AY598924 & CBS 125418 \\
\hline Sterile mycelia sp. UI-6 & Punctate & 2 & 3 & PA1 3E1d & FJ438385 & FJ147172 & CBS125316 \\
\hline Sterile mycelia sp. RS5.2 (Stomiopeltis) & Ramose & 5 & 28 & NC1 18C1d & FJ438376 & FJ147164 & CBS125317 \\
\hline Sterile mycelia sp. RS5.1 (Stomiopeltis) & Ramose & 2 & 2 & GA3 23C2b & FJ438375 & FJ147163 & na \\
\hline Sybren sp. CS1 & Compact speck & 14 & 47 & KY3 15E1b & FJ438388 & FJ147175 & CBS 125660 \\
\hline Yeast sp. UI-10 & Punctate & 1 & 2 & MI2 34E2b & FJ438387 & FJ147174 & CBS 125661 \\
\hline Zygophiala sp. FS1.9 & Flyspeck & 4 & 4 & NY3 16A1a & FJ425207 & FJ147156 & CBS125318 \\
\hline Zygophiala cryptogama & Flyspeck & 5 & 14 & OH4 1A1a & FJ425208 & FJ147157 & CBS 125658 \\
\hline Zygophiala sp. FS6 & Flyspeck & 3 & 6 & KY4 17.2A1a & na & FJ147159 & CBS125319 \\
\hline Zygophiala tardicrescens & Flyspeck & 1 & 4 & MWA1a & AY598856 & EF164901 & CBS 118946 \\
\hline Zygophiala wisconsinensis & Flyspeck & 5 & 11 & OH4 9A1c & FJ425209 & FJ147158 & CBS 125659 \\
\hline
\end{tabular}


Peltaster fructicola, and Pseudocercosporella sp. RH1, each of which occurred in more than half of the orchards sampled (Table 2). Geastrumia polystigmatis was one of the most prevalent species in the 2005 survey but was not found in the 2000 survey. Only 9 of the 60 species $(15 \%)$ occurred in $>10$ orchards, whereas 41 species $(70 \%)$ each occurred in $<4$ orchards, 30 species $(50 \%)$ occurred in 2 orchards, and 19 species $(31.7 \%)$ were found in only a single orchard.

The number of species per orchard varied from 2 to 15 , with a mean of 7.7 (Table 1). Number of SBFS species and values of diversity indexes were significantly $(P<0.0001)$ lower in orchards that had received synthetic chemical fungicide sprays on a protectant schedule during the fruit maturation period than in orchards that had not received fungicide sprays during this period. No diversity comparisons were made with orchards that had received sprays of organically certified fungicides during the fruit maturation period due to the small sample size (two orchards), and fungicide-spray records could not be obtained for 2 of the 39 orchards sampled.

For the entire data set, orchards located west of longitude $84.6^{\circ} \mathrm{W}$ (west of the Appalachian Mountains) had significantly $(P=0.0171)$ more SBFS species per orchard and higher values of Shannon and Margalef indexes $(P=0.0015$ and 0.0512 , respectively) than orchards east of that meridian. Unsprayed western orchards had an average of 11.0 species whereas unsprayed eastern orchards averaged 8.6 species. Orchards south of latitude $39.5^{\circ} \mathrm{N}$ did not differ significantly from orchards to the north of this parallel in number of species or Shannon and Margalef index values $(P=0.2931,0.6010$, and 0.7924 , respectively). Mean number of species per orchard was 7.2 in the north compared with 8.3 in the south, and unsprayed northern orchards had an average of 9.6 species compared with 11.0 species in southern orchards.

These regions were then further subdivided by the same latitude and longitude lines into four quadrants designated as South Central (SC), North Central (NC), Southeast (SE), and Northeast (NE) (Table 3). Results of $F$ tests comparing all orchards in the four geographic regions differed significantly for number of species as well as values of Shannon and Margalef indexes $(P=$ $0.0351,0.0086$, and 0.0007 , respectively). The $\mathrm{SC}$ region had the most species per orchard, whereas the SC and NC regions had the highest Shannon Index values (Table 3). The average Margalef Index value was significantly higher in the SC than the SE region. When comparing only orchards that had been sprayed with fungicides, however, the number of SBFS species per orchard did not differ among the four regions.

Biogeography. Several SBFS species, including Schizothyrium pomi, Peltaster fructicola, and Pseudocercosporella sp. RH1, were nearly ubiquitous throughout the area of the two surveys (Fig. 4). Species in the same genus sometimes had sharply differ- ent geographic ranges. For example, Zygophiala cryptogama did not occur outside the Midwest and Upper South (Tennessee and Kentucky), Peltaster sp. P2.2 had a similar distribution, and Pseudocercosporella sp. RH3 was not found in the Upper Midwest (M. M. Díaz Arias, unpublished data). Examples of other species that were found only within restricted geographic regions included Stomiopeltis sp. RS5.2 (southern states only), Phialophora sessilis, Geastrumia polystigmatis (Southeast, Mid-Atlantic, and Northeast), Ramularia sp. P5 (Ohio River Valley to New England), Sybren sp. CS1 (all regions except New England), and Colletogloeum sp. FG2.1 (Midwest and Upper South) (Fig. 5). It was not possible to generalize about geographic distribution of SBFS species that were found in only one or two orchards.

\section{DISCUSSION}

The results document that the SBFS complex is far more taxonomically diverse than previously recognized. Using molecular genetic analysis in combination with morphological characterization, we documented 60 putative species in the eastern half of the United States alone, compared with 4 that had been identified previously using morphological criteria (46). The 2005 survey doubled the number of SBFS species from the 30 previously documented in the 2000 survey (5). More intensive surveys of U.S. orchards are likely to reveal additional SBFS species (12, 34 ), and surveys in other countries indicate that the worldwide SBFS complex is substantially more diverse than the assemblage documented in the United States $(4,36,37)$.

Several consistent patterns are evident in SBFS taxonomic diversity. Most U.S. species of SBFS are in the order Capnodiales, with some widely occurring exceptions, including Geastrumia polystigmatis and Sybren sp. CS1. Many of the putative species recovered in the 2005 survey were in the same genera as those from the 2000 survey. Furthermore, preliminary surveys in China and Europe have found some of the same or closely related species, based on ITS sequences, as those reported from the United States $(4,22,35)$. This suggests that the majority of the SBFS worldwide complex can be expected to be Capnodiales.

Our findings offer strong support for revising the long-standing perception of SBFS as two distinct diseases, "sooty blotch" and "flyspeck," each caused by one or a few species of fungi $(39,46)$. It is now evident that SBFS is caused by a highly diverse assemblage of fungi, with as many as 20 species sharing a single mycelial type on apple fruit. Although mycelial type appears to be a consistent character for each species based on current evidence, the seven recognized mycelial types constitute a continuum between so-called sooty blotch and flyspeck morphologies rather than two distinct groups (5). Furthermore, although the ecology and epidemiology of most SBFS species has not been studied,

TABLE 3. Biodiversity of sooty blotch and flyspeck fungi in apple orchards in four subregions of eastern North America ${ }^{\mathrm{v}}$

\begin{tabular}{|c|c|c|c|c|c|c|c|c|c|}
\hline \multirow[b]{2}{*}{ Region $^{\mathrm{w}}$} & \multicolumn{3}{|c|}{ Average no. of species per orchard ${ }^{\mathrm{x}}$} & \multicolumn{3}{|c|}{ Average Shannon Index ${ }^{y}$} & \multicolumn{3}{|c|}{ Average Margalef Index ${ }^{\mathrm{Z}}$} \\
\hline & All & Spray & No spray & All & Spray & No spray & All & Spray & No spray \\
\hline $\mathrm{SC}$ & $10.86 \mathrm{a}$ & 6.00 & $11.67 \mathrm{a}$ & $2.48 \mathrm{a}$ & 1.43 & $2.60 \mathrm{a}$ & $1.22 \mathrm{a}$ & 0.71 & $1.31 \mathrm{a}$ \\
\hline $\mathrm{NC}$ & $7.75 \mathrm{~b}$ & 6.00 & $9.67 \mathrm{ab}$ & $2.38 \mathrm{a}$ & 2.02 & $2.75 \mathrm{a}$ & $0.96 \mathrm{ab}$ & 0.69 & $1.28 \mathrm{a}$ \\
\hline SE & $6.64 \mathrm{~b}$ & 6.00 & $9.50 \mathrm{ab}$ & $1.62 \mathrm{~b}$ & 1.42 & $2.48 \mathrm{ab}$ & $0.80 \mathrm{~b}$ & 0.76 & $1.02 \mathrm{~b}$ \\
\hline $\mathrm{NE}$ & $6.85 \mathrm{~b}$ & 6.00 & $8.67 \mathrm{~b}$ & $1.55 \mathrm{~b}$ & 1.30 & $1.95 \mathrm{~b}$ & $0.86 \mathrm{ab}$ & 0.80 & $0.95 \mathrm{~b}$ \\
\hline LSD & 2.74 & $\ldots$ & 2.59 & 0.71 & $\ldots$ & 0.63 & 0.38 & $\ldots$ & 0.25 \\
\hline
\end{tabular}

${ }^{\mathrm{v}}$ Orchards were divided on the basis of spray programs: All $=$ all 39 orchards regardless of spray program; Spray $=$ fungicides sprayed during fruit maturation period; No spray $=$ no fungicides sprayed during this period. Numbers in a column followed by the same letter are not significantly different (least significant difference [LSD], $P<0.05)$. An $F$ test showed no significant differences among regions for orchards sprayed with fungicides.

${ }^{\text {w }}$ Orchards were grouped into four regions, divided by longitude $84.6^{\circ} \mathrm{W}$ and latitude $39.5^{\circ} \mathrm{N}$ : South Central (SC) (orchards IL2, IL3, KY1,KY2, KY3, MO2, and TN1), Southeast (SE) (orchards GA2, GA3, KY4, NC1, NC2, NC3, NC4, VA1, VA2, VA3, and VA5), North Central (NC) (orchards IA1, IA2, IA3, IL1, MI2, MI3, MO1, and WI1), and Northeast (NE) (orchards MA1, MA2, MA3, MA4, MA5, NY1, NY2, NY3, OH1, OH3, OH4, PA1, and PA2).

${ }^{x}$ Number of putative species based on internal transcribed spacer genotype and isolate morphology, then verified using modified Koch's postulates.

y Shannon Index incorporates species richness with the estimated proportion of individuals of a given species to the total number of individuals in the orchard (relative abundance) (33).

${ }^{\mathrm{z}}$ Margalef Index is derived using a combination of the number of species derived and the total number of individuals summed over all species (30). 
some are distinct from each other in temperature tolerance, nutritional response, fungicide sensitivity, phenology, and tendency to be dislodged from the apple surface by postharvest dip treatments followed by brushing $(6,19,24,27,34,41,47)$. To achieve more efficient management of SBFS on apple fruit, it may be necessary to account for interspecies differences in environmental biology and discard the outmoded two-disease paradigm.

This report is the first to describe patterns of SBFS species diversity in and among orchards. In previous studies, knowledge of species diversity was constrained by inability to conclusively identify some of the component species. Our findings regarding the impact of fungicide use on species diversity are robust because the differences were statistically significant for all three diversity indexes. Fungicide sensitivity can vary at least 20 -fold among SBFS species (41); therefore, SBFS species that are relatively sensitive to commonly used fungicides may be rare or absent in regularly sprayed orchards. Indirect evidence supporting this idea is the fact that unsprayed orchards were the source of 13 of the 19 SBFS species (68\%) that were found in only a single orchard; in other words, rare species occurred primarily in unsprayed orchards.
Although higher SBFS diversity was found in western than eastern orchards, the reasons for this difference are unclear. More intensive regional surveys, incorporating larger numbers of sprayed and unsprayed orchards, will be needed to clarify possible regional patterns of SBFS biodiversity.

Our study is also the first to clearly describe biogeographic patterns of individual SBFS species occurrence on a regional scale. Hints of these patterns were evident in results of previous surveys $(26,38)$ but combining morphological and genetic data allowed us to identify a larger segment of the SBFS complex. In our surveys, certain species were cosmopolitan throughout much of the eastern half of the United States, including Schizothyrium pomi and Peltaster fructicola. Johnson et al. (26) also found that Peltaster fructicola occurred widely in the southeastern, midwestern, and northeastern United States. In contrast, other species in our surveys were regionally restricted in geographic range (e.g., Geastrumia polystigmatis and Colletogloeum sp. FG2.1). The factors determining region-specific geographic patterns are uncertain. One possible contributing factor could be interspecific differences in temperature tolerance. The fact that SBFS historically has been uncommon in the northern margin of the applegrowing region of northeastern North America-central and

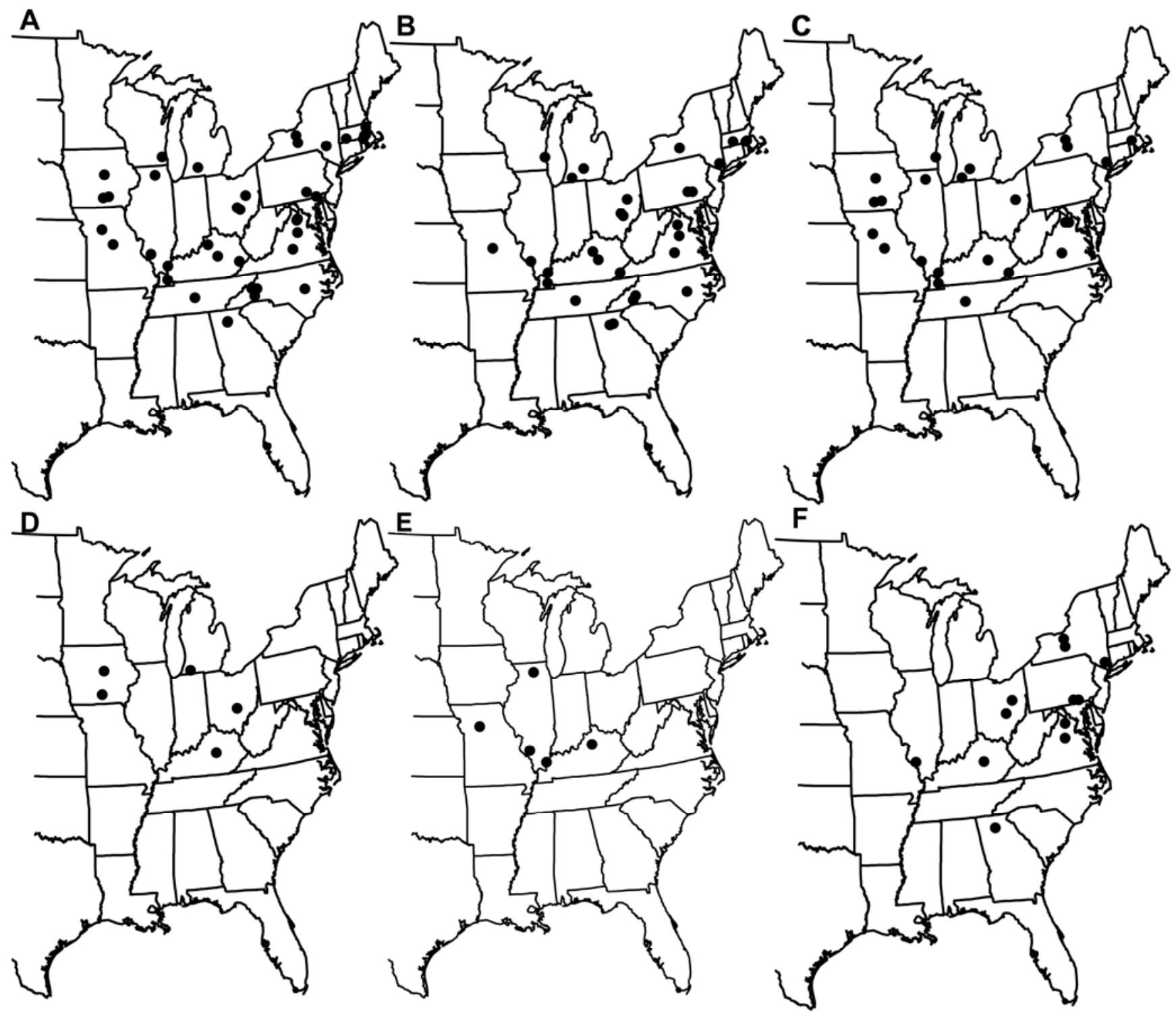

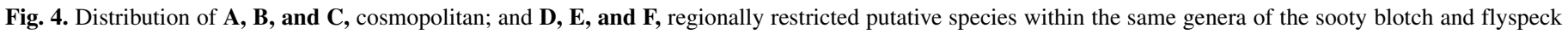

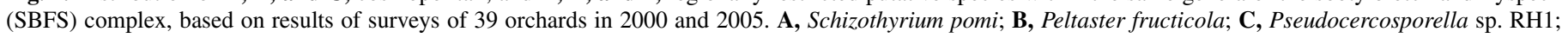
D, Zygophiala cryptogama; E, Peltaster sp. P2.2; and F, Pseudocercosporella sp. RH3. 

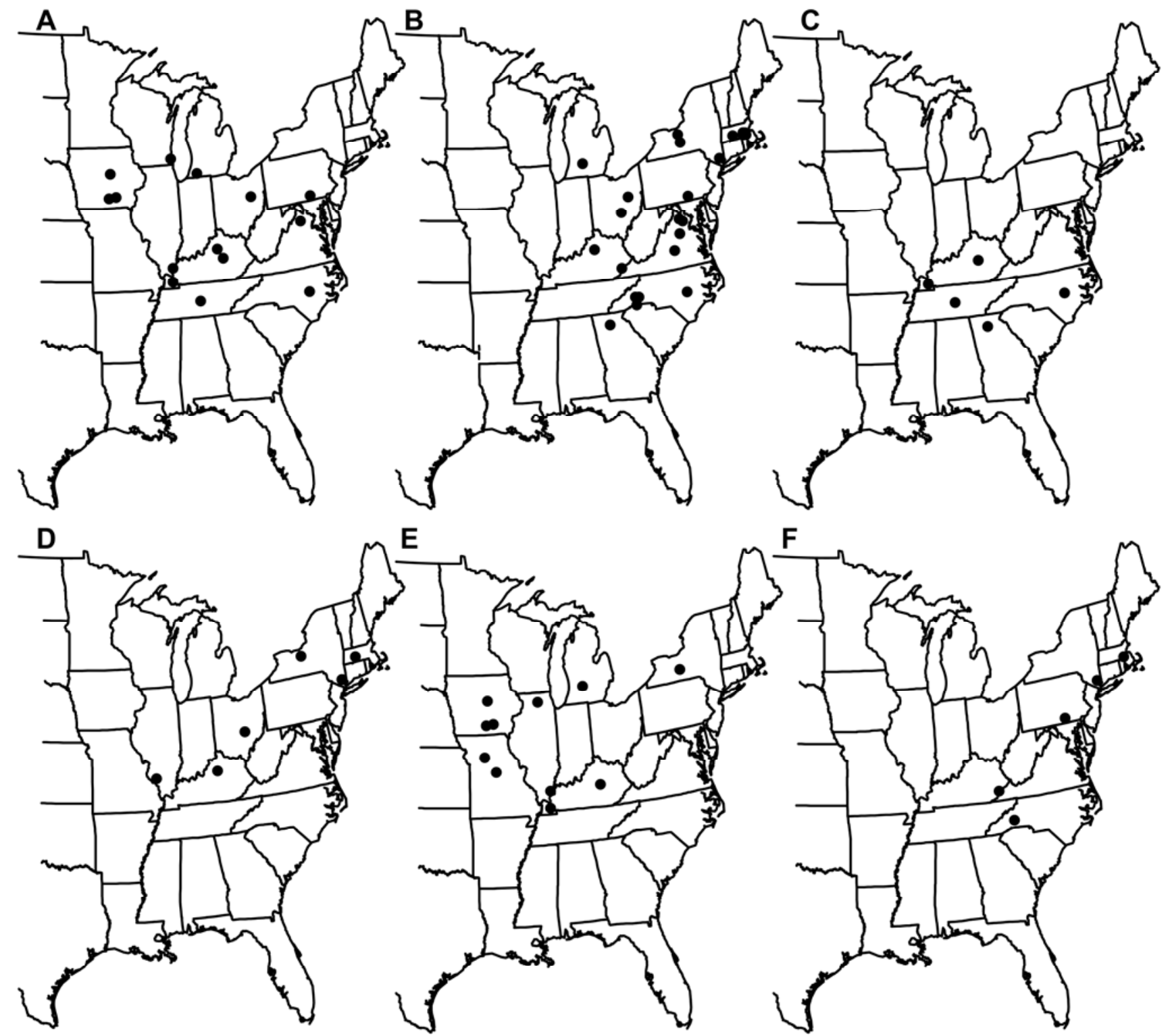

Fig. 5. Distribution of six regionally-limited putative species in the sooty blotch and flyspeck (SBFS) complex, based on results of surveys of 39 orchards in 2000 and 2005. A, Sybren sp. CS1; B, Geastrumia polystigmatis; C, Stomiopeltis sp. RS5.2; D, Ramularia sp. CS2; E, Colletogloeum sp. FG2.1; and F, Phialophora sessilis.

northern portions of Minnesota, Wisconsin, Michigan, New York, and northern New England-despite adequately warm and moist summer conditions for SBFS development suggests either inability of SBFS species to survive extremely cold winter temperatures or a growing season that is too short to produce visible SBFS colonies. Regional differences in the assemblage of reservoir host species surrounding orchards could also potentially impact SBFS species distribution. The present study provides a foundation for future research by establishing that some SBFS species display marked patterns of geographic distribution.

By combining morphological characterization with genetic analysis tools, it should now be possible to pinpoint which SBFS species pose the greatest economic threat in each region, and then to focus epidemiological studies on these key species. Using specific primers and RFLPs, for example, phenological studies of the SBFS assemblage in six Iowa orchards showed that the same two species were the first to appear on apple fruit in all the surveyed orchards (34). Because disease-warning systems for SBFS $(7,11)$ are built around timing fungicide sprays to avoid outbreaks of these earlyappearing species, identifying them is likely to be an important step toward achieving more cost-effective disease management.

\section{ACKNOWLEDGMENTS}

We thank K. Hemnani for technical assistance and the cooperating growers for allowing us to sample apple fruit in their orchards.

\section{LITERATURE CITED}

1. Babadoost, M., Gleason, M. L., McManus, P. S., and Helland, S. J. 2004. Evaluation of a wetness-based warning system and reduced-risk fungicides for management of sooty blotch and flyspeck of apple. HortTechnology 14:27-33.

2. Baines, R. C., and Gardner, M. W. 1932. Pathogenicity and hosts of the sooty blotch fungus of apple. Phytopathology 22:937-952.

3. Batzer, J. C., Díaz-Arias, M. M., Harrington, T. C., Gleason, M. L., Groenewald, J. Z., and Crous, P. W. 2008. Four species of Zygophiala (Schizothyriaceae, Capnodiales) are associated with the sooty blotch and flyspeck complex on apple. Mycologia 100:246-258.

4. Batzer, J. C., Feldmann, T. M., Gleason, M. L., and Oertel, B. 2006. Comparison of diversity in the sooty blotch and flyspeck apple disease complex in Germany and the U.S.A. based on parsimony analysis of ribosomal DNA. (Abstr.) Phytopathology 96:S10.

5. Batzer, J. C., Gleason, M. L., Harrington, T. C., and Tiffany, L. H. 2005. Expansion of the sooty blotch and flyspeck complex on apples based on analysis of ribosomal DNA gene sequences and morphology. Mycologia 
97:1268-1286.

6. Batzer, J. C., Gleason, M. L., Weldon, B., Dixon, P. M., and Nutter, F. W., Jr. 2002. Evaluation of postharvest removal of sooty blotch and flyspeck on apples using sodium hypochlorite, hydrogen peroxide with peroxyacetic acid, and soap. Plant Dis. 86:1325-1332.

7. Brown, E. M., and Sutton, T. B. 1995. An empirical model for predicting the first symptoms of sooty blotch and flyspeck of apples. Plant Dis. 79:1165-1168

8. Chapin, F. S., III. 1980. The mineral nutrition of wild plants. Annu. Rev. Ecol. Syst. 11:233-260.

9. Colby, A. S. 1920. Sooty blotch of pomaceous fruits. Trans. Ill. State Acad. Sci. 13:139-175.

10. Díaz Arias, M. M. 2007. Biogeografía y diversidad genética de las especies del complejo fúngico mancha negra ("Sooty blotch") y mancha de la mosca ("Flyspeck") de la manzana en la región este de los Estados Unidos. Tesis de Maestría, Universidad de Costa Rica, San José, Costa Rica.

11. Duttweiler, K. B., Gleason, M. L., Dixon, P. M., Sutton, T. B., McManus, P. S., and Monteiro, J. E. B. A. 2008. Adaptation of an apple sooty blotch and flyspeck warning system for the Upper Midwest United States. Plant Dis. 92:1215-1222.

12. Duttweiler, K. B., Sun, G. Y., Batzer, J. C., Harrington, T. C., and Gleason, M. L. 2008. An RFLP-based technique for identifying fungi in the sooty blotch and flyspeck complex on apple. Plant Dis. 92:794-799.

13. Eriksson, O. E., ed. 2006. Classification of the Ascomycetes. Myconet 12:1-82. Available from www.fieldmuseum.org/myconet/

14. Eriksson, O. E., and Winka, K. 1997. Supraordinal taxa of Ascomycota. Myconet 1:1-Available from www.fieldmuseum.org/myconet/

15. Feldmann, T. 2006. Biological, Chemical and Physiological Studies on Epiphytic Asco- and Deuteromycetes as Causal Organisms of Sooty Blotch and Pink Rot in Apple Fruit. Cuvillier Verlag, Gottingen, Germany.

16. Hall, T. A. 1999. BioEdit: A user-friendly biological sequence alignment editor and analysis program for Windows 95/98/NT. Nucleic Acids. Symp. Ser. 41:95-98.

17. Harrington, T. C., and Wingfield, B. D. 1995. A PCR-based identification method for species of Armillaria. Mycologia 87:280-288.

18. Hartman, J. R. 1996. Evaluation of fungicide timing for sooty blotch and flyspeck control, 1995. Fungic. Nematicide Tests 51:6.

19. Hernández, S. 2005. Response of sooty blotch and flyspeck complex to optimum temperature and post-harvest removal on apples by brushing combined with dip treatments. M.S. thesis, Iowa State University, Ames.

20. Hickey, K. D. 1960. The sooty blotch and flyspeck diseases of apple with emphasis on variation within Gloeodes pomigena (SCW.) Colby. Ph.D. thesis, The Pennsylvania State University, State College.

21. Hooper, D. U., Solan, M., Symstad, A., Diaz, S., Gessner, M. O., Buchmanm N., Degrange, V., Grime, P., Hulot, F., Mermillod-Blondin, F., Roy, J., Spehn, E., and van Peer, L. 2002. Species diversity, functional diversity, and ecosystem functioning. Pages 195-279 in: Biodiversity and Ecosystems Functioning: Synthesis and Perspectives. S. Loreau, P. Naeem, and P. Inchausti, eds. Oxford University Press, Oxford.

22. Ivanovic, M., Latinovic, J., Latinovic, N., Batzer, J. C., Hemnani, K., and Gleason, M. L. 2008. Diversity of sooty blotch and flyspeck fungi from Serbia and Montenegro. (Abstr.) Phytopathology 98:S72.

23. Johnson, E. M., and Sutton, T. B. 1994. First report of Geastrumia polystimgatis on apple and common blackberry in North America. Plant Dis. 78:1219.

24. Johnson, E. M., and Sutton, T. B. 2000. Response of two fungi in the apple sooty blotch complex to temperature and relative humidity. Phytopathology 90:362-367.

25. Johnson, E. M., Sutton, T. B., and Hodges, C. S. 1996. Peltaster fructicola: A new species in the complex of fungi causing apple sooty blotch. Mycologia 88:114-120.

26. Johnson, E. M., Sutton, T. B., and Hodges, C. S. 1997. Etiology of apple sooty blotch disease in North Carolina. Phytopathology 87:88-95.
27. LeCorronc, F., Batzer, J. C., and Gleason, M. L. 2006. Effect of apple juice on in vitro morphology of four newly discovered fungi in the sooty blotch and flyspeck complex. (Abstr.) Phytopathology 96:S65.

28. Lumbsch, H. T., and Huhndorf, S. 2007. Whatever happened to the pyrenomycetes and loculoascomycetes? Mycol. Res.111:1064-1074.

29. Lumbsch, H. T., Schmitt, I., Lindemuth, R., Miller, A., Mangold, A., Fernandez, F., and Huhndorf, S. 2005. Performance of four ribosomal DNA regions to infer higher-level phylogenetic relationships of inoperculate euascomycetes (Leotiomyceta). Mol. Phylogenet. Evol. 34:512-24.

30. Magurran, A. E. 1988. Ecological Diversity and Its Measurement. University Press, Cambridge.

31. Rosenberger, D. A., Engle, C. A., and Meyer, F. W. 1996. Effects of management practices and fungicides on sooty blotch and flyspeck diseases and productivity of Liberty apples. Plant Dis. 80:798-803.

32. Schoch, C., Shoemaker, R. A, Seifert, K., Hambleton, S., Spatafora, J. W., and Crous, P. W. 2006. A multigene phylogeny of the Dothideomycetes using four nuclear loci. Mycologia 98:1041-1052.

33. Shannon, C. E., and Weaver, W. 1949. The Mathematical Theory of Communication. University of Illinois Press, Urbana.

34. Sisson, A. J., Batzer, J. C., Waxman, K. B., Hemnani, K., and Gleason, M. L. 2008. Phenology of sooty blotch and flyspeck fungi on apples in Iowa. (Abstr.) Phytopathology 98:S147.

35. Sun, G. Y., Batzer, J. C., Zhang, Y. M., and Gleason, M. L. 2004. Comparison of fungi in sooty blotch and flyspeck apple disease complex in Shaanxi province China and U.S. based on ribosomal DNA. (Abstr.) Phytopathology 94:S100.

36. Sun, G. Y., Leandro, L. F., Batzer, J. C., Harrington, T. C., and Gleason, M. L. 2004. Specific PCR primers to identify sooty blotch and flyspeck fungi on apple in the Midwest U.S. (Abstr.) Phytopathology 94:S100.

37. Sun, G. Y., Zhang, M., Zhang, R., Ma, H., and Gleason, M. L. 2006. Wallemia - a genus newly recorded from China. Mycotaxon 95:277-280.

38. Sutton, A. L., and Sutton, T. B. 1994. The distribution of mycelial types of Gloeodes pomigena on apples in North Carolina and their relationship to environmental conditions. Plant Dis. 78:668-673.

39. Sutton, T. B. 1990. Sooty blotch and flyspeck. Pages 20-22 in: Compendium of Apple and Pear Diseases. A. L. Jones and H. S. Aldwinckle, eds. American Phytopathological Society, St. Paul, MN.

40. Swofford, D. L. 2002. PAUP. Phylogenetic Analysis Using Parsimony (and Other Methods), Version 4.0. Sinauer Associates, Sunderland, MA.

41. Tarnowski, T., Batzer, J., Gleason, M., Helland, S., and Dixon, P. 2003. Sensitivity of newly identified clades in the sooty blotch and flyspeck complex on apple to thiophanate-methyl and ziram. Online. Plant Health Progress doi:10.1094/PHP-2003-12XX-01-RS.

42. Thompson, J. D., Gibson, T. J., Plewniak, F., Jeanmougin, F., and Higgins, D. G. 1997. The CLUSTAL-X windows interface: Flexible strategies for multiple sequence alignment aided by quality analysis tools. Nucleic Acids Res. 25:4876-4882.

43. Vilgalys, R., and Hester, M. 1990. Rapid genetic identification and mapping of enzymatically amplified ribosomal DNA from several Cryptococcus species. J. Bacteriol. 172:4239-4246.

44. von Arx, J. A. 1959. Ein Beitrag zur Kenntnis der Fliegenfleckenpilze. Proc. K. Ned. Akad. Wet. Ser. C. 62:333-340.

45. White, T. J., Bruns, T., Lee, S., and Taylor, J. 1990. Amplification and direct sequencing of fungal ribosomal RNA genes for phylogenetics. Pages 315-322 in: PCR Protocols: A Guide to Molecular Methods and Applications. M. A. Innis, D. H. Gelfand, J. J. Sninsky, and J. W. White, eds. Academic Press, San Diego, CA and New York.

46. Williamson, S. M., and Sutton, T. B. 2000. Sooty blotch and flyspeck of apple: Etiology, biology, and control. Plant Dis. 84:714-724.

47. Wrona, B. R. 2004. Influence of fruit surface on the growth of fungi that cause sooty blotch of apple. J. Plant Prot. Res. 44:283-288.

48. Wrona, B. R., and Grabowski, M. 2004. Etiology of apple sooty blotch in Poland. J. Plant Prot. Res. 44:293-297. 